\title{
Real-Time Analysis of Secondary Organic Aerosol Particles Formed from Cyclohexene Ozonolysis Using a Laser-Ionization Single- Particle Aerosol Mass Spectrometer
}

\author{
Masahiro Narukawa,* Yutaka Matsumi, *† Jun Matsumoto,* Kenshi TaKahaShi,* \\ Akihiro YabuShita, $* *$ Kei SATO, $* * *$ and Takashi ImAMURA*** \\ *Solar-Terrestrial Environment Laboratory, Nagoya University, 3-13 Honohara, \\ Toyokawa, Aichi 442-8507, Japan \\ **Horiba, Ltd., 2 Miyanohigashi, Kisshoin, Minami, Kyoto 601-8510, Japan \\ ***National Institute for Environmental Studies, 16-2 Onogawa, Tsukuba, Ibaraki 305-8506, Japan
}

\begin{abstract}
A real-time analysis of secondary organic aerosol (SOA) particles formed from cyclohexene ozonolysis in a smog chamber was performed using a laser-ionization single-particle aerosol mass spectrometer (LISPA-MS). The instrument obtains both size and chemical compositions of individual aerosol particles with a high time-resolution $(\sim 2 \mathrm{~s}$ at the maximum). Both positive and negative-ion mass spectra are obtained. Standard particles generated from dicarboxylic acid solutions using an atomizer were also analyzed. For both standard and SOA particles, the negative-ion mass spectra provided information about the molecular weights of the organic compounds in the particles, since the intense ions in the negative-ion mass spectra are mainly attributable to the molecular-related ions $[\mathrm{M}-\mathrm{H}]^{-}$. It was demonstrated that the realtime single-particle analysis of SOA particles by the LISPA-MS technique can reveal the formation and transformation processes of SOA particle in smog chambers.
\end{abstract}

(Received February 8, 2007; Accepted March 14, 2007; Published May 10, 2007)

\section{Introduction}

Organic compounds significantly contribute up to $\sim 20-50 \%$ of the total mass of fine atmospheric aerosols (sub-micron) at continental mid-latitudes. ${ }^{1}$ Model studies indicate that the source of the main fraction of organic aerosols is of secondary origin; ${ }^{2}$ namely, most organic aerosols are chemically formed in the atmosphere. The chemistry of secondary organic aerosol (SOA) formation has been studied using smog chambers. ${ }^{3}$ Chemical compositions of SOA particles formed in chambers have been studied using off-line techniques, which have provided important information about the chemical compositions. However, the off-line techniques are timeconsuming and tend to have sampling artifacts. ${ }^{4}$ In addition, it is difficult to measure the size and chemical compositions of the individual SOA particles simultaneously and in real time by using the off-line techniques.

From the mid 1990s, real-time aerosol mass spectrometry has been remarkably developed. Most of those instruments can size, count, and mass-analyze individual particles with high time-resolution. Among such instruments, NOAA's particle

† To whom correspondence should be addressed.

E-mail: matsumi@stelab.nagoya-u.ac.jp

J. M. present address: Integrated Research Institute, Tokyo Institute of Technology, 4259 Nagatsuta, Midori, Yokohama 226-8503, Japan.

K. T. present address: Kyoto University Pioneering Research Unit for Next Generation, Kyoto University, Gokasho, Uji, Kyoto 611-0011, Japan. analysis by laser mass spectrometer (PALMS), ${ }^{5}$ University of California at San Diego's aerosol ttime-of-flight mass spectrometer (ATOFMS), ${ }^{6}$ University of Delaware's rapid single-particle mass spectrometer II (RSMS-II), ${ }^{7}$ and Aerodyne's aerosol mass spectrometer $(\mathrm{AMS})^{8}$ were operated together during the Atlanta Supersite Project to characterize the performance of the instruments. ${ }^{9}$ Although those mass spectrometers used in Atlanta are generally classified as similar instruments, they clearly have different characteristics due to their unique designs. ${ }^{9}$ Reviews of real-time aerosol mass spectrometry are available in the literature..$^{10,11}$

We have recently developed a laser-ionization single-particle aerosol mass spectrometer (LISPA-MS) for real-time singleparticle measurements. The LISPA-MS is capable of high timeresolution measurements of the size and chemical compositions of individual particles. Either the positive or negative-ion mass spectra are obtained for individual particles by changing the voltage polarity of the instrument. The LISPA-MS has a simple inlet and optical design, so that all particles detected by scattered light are virtually hit by desorption/ionization laser pulses. Apparent changes in the chemical compositions of Asian dust particles transported from the Asian continent to Japan were captured by the LISPA-MS. ${ }^{12}$

Here, we present the application of the LISPA-MS to the study of SOA particles formed in a smog chamber. The chemical compositions of the SOA particles formed from cyclohexene ozonolysis have been analyzed using the LISPAMS. Cyclohexene is a simple surrogate for understanding the behavior of more complex terpenoid species that are emitted to the atmosphere as biogenic hydrocarbons. The major chemical compositions of SOA particles formed from cyclohexene 


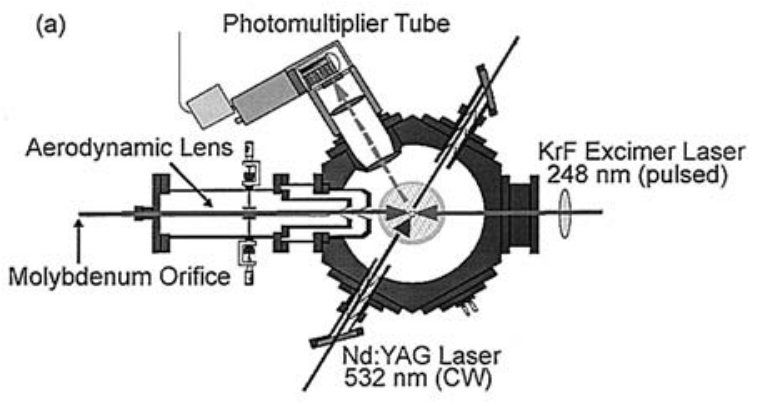

(b)

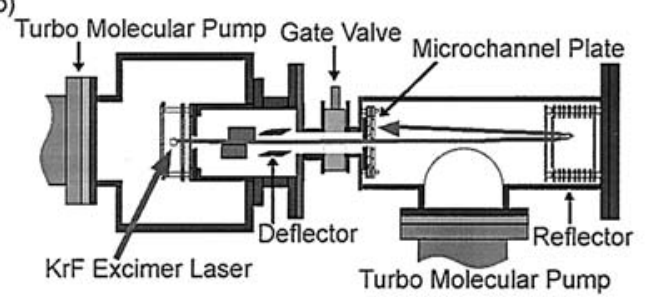

Fig. 1 Diagrams of (a) the particle inlet and the ion source region of the laser-ionization single-particle aerosol mass spectrometer (LISPA-MS) and (b) the ion source region and reflectron time-offlight mass spectrometer of the LISPA-MS.

ozonolysis have been extensively studied. ${ }^{13-18}$ The mass spectra of standard particles generated from dicarboxylic acid solutions using an atomizer were also measured for the sake of analysis of the mass spectra of the SOA particles in the chamber experiments. It will be demonstrated that the LISPA-MS technique is a useful tool to reveal the formation and transformation processes of SOA particles in smog chambers.

\section{Experimental}

Laser-ionization single-particle aerosol mass spectrometer (LISPA-MS)

A schematic diagram of the particle inlet and the ion source region of the LISPA-MS is shown in Fig. 1a. Aerosol particles are introduced into an aerodynamic lens through a flow-limiting molybdenum orifice with a diameter of $300 \mu \mathrm{m}$. In the reduced pressure region, particles are horizontally focused into a narrow particle beam $(\sim 1 \mathrm{~mm}$ diameter $)$ in the center of the gas flow by the aerodynamic lens. ${ }^{19}$ The aerodynamic lens is a $15 \mathrm{~mm}$ inside diameter and $300 \mathrm{~mm}$ long stainless-steel tube with six orifices (3-5 mm diameter) inside. After exiting the lens, the particle beam is transmitted into the ion source region through differentially pumped stages with two skimmers (Precision Instrument Services). The first skimmer has an aperture of 1 $\mathrm{mm}$ and the second $0.7 \mathrm{~mm}$. The pressure of the ion source region is decreased to $\sim 10^{-3} \mathrm{~Pa}$ when the flow rate of sample air is $\sim 700 \mathrm{sccm}$ ( $\mathrm{cc} \mathrm{min}{ }^{-1}$ under standard conditions).

For detecting the particles introduced into the ion source region, a continuous-wave laser beam, produced by a frequency-doubled Nd:YAG laser at $532 \mathrm{~nm}(100 \mathrm{~mW})$, crosses the particle beam at an angle of $60^{\circ}$, as shown in Fig. 1a. The scattered light from the individual particles at $532 \mathrm{~nm}$ is detected by a photomultiplier tube (PMT, Hamamatsu, 1P28A), which is aligned at an angle of $60^{\circ}$ with the particle beam and with the detection laser beam. A set of two quartz lenses (50 $\mathrm{mm}$ diameter) focuses the scattered light onto the photocathode, and a bandpass filter is installed just in front of the PMT. The
Table 1 Initial conditions for cyclohexene ozonolysis in the NIES smog chamber

\begin{tabular}{ccccc}
\hline Run No. & $P_{0} /$ Torr & $T_{0} / \mathrm{K}$ & {$[\text { cyclohexene }]_{0} / \mathrm{ppmv}$} & {$\left[\mathrm{O}_{3}\right]_{0} / \mathrm{ppmv}$} \\
\hline 1 & 769 & 298 & 2.08 & 1.83 \\
2 & 762 & 299 & 2.00 & 2.00 \\
3 & 761 & 299 & 2.01 & 1.91 \\
4 & 762 & 299 & 2.00 & 1.94 \\
\hline
\end{tabular}

intensity of the scattered light is approximately proportional to the particle size, and is utilized for roughly determining the particle size. The particle size calibration of the LISPA-MS is determined by sampling dry polystyrene latex particles (Duke Scientific and JSP). The detection efficiency for particles smaller than the wavelength of the detection laser light is very low due to the Mie scattering process. Thus, the lower limit of the detected particle diameter is $\sim 200 \mathrm{~nm}$. The signals from the PMT are amplified and discriminated, and those above a selectable threshold level trigger desorption/ionization laser pulses. A pulsed $\mathrm{KrF}$ excimer laser at $248 \mathrm{~nm}$ (Lambda Physik, OPTex) is used as a light source for the desorption/ionization of particles. As shown in Fig. 1a, the $248 \mathrm{~nm}$ laser beam is aligned collinearly with the particle beam and focused by a quartz lens ( $f=300 \mathrm{~mm}$ ) onto the center of the ion source region. The irradiation of the $248 \mathrm{~nm}$ laser pulse is delayed by $1.8 \mu$ s after the detection of scattered light to distinguish the PMT signals of the detection laser and of the desorption/ionization laser. During this period, the detected particles barely move $(<1 \mathrm{~mm})$ along the collinear line. Therefore, the desorption/ionization of the particles virtually takes place at the center of the ion source region. The pulse energy of the $248 \mathrm{~nm}$ laser is $\sim 1-2 \mathrm{~mJ}$ with $20 \mathrm{~ns}$ pulse duration, which provides a power density of $\sim 1 \times$ $10^{7} \mathrm{~W} \mathrm{~cm}^{-2}$ when the laser spot size is $1 \mathrm{~mm}$.

A schematic diagram of the ion source region and reflectron time-of-flight mass spectrometer of the LISPA-MS is shown in Fig. 1b. The resultant ions are accelerated from the ion source region to the reflector assembly, and are then detected by a microchannel plate detector (MCP, Hamamatsu). Time-offlight mass spectrometry (TOF-MS) is well suited to the pulsed nature of the desorption/ionization laser. The pressure in the TOF-MS chamber is $\sim 10^{-5} \mathrm{~Pa}$. By monitoring the ion current from the MCP as a function of time, a complete mass spectrum is obtained for the chemical compositions of a single particle. The ion signals from the detector are amplified linearly, digitized, and recorded as mass spectra with a high timeresolution ( $\sim \mathrm{s}$ at the maximum). Either the positive or negative-ion mass spectra are obtained for individual particles by changing the voltage polarity of the ion source region and the TOF-MS.

\section{Smog chamber experiments}

Laboratory studies were conducted by using an indoor evacuable and bakable photochemical smog chamber at National Institute for Environmental Studies (NIES). The chamber is a stainless-steel cylinder having a volume of 6.065 $\mathrm{m}^{3}$, a length of $3500 \mathrm{~mm}$ and an inner diameter of $1450 \mathrm{~mm}$. The inner surface of the chamber is Teflon-coated (tetrafluoroethylene-perfluoroalkyl vinyl ether copolymer). The chamber has $20 \mathrm{~m}^{2}$ of a Teflon-coated surface and $2 \mathrm{~m}^{2}$ of a glass and quartz surface, resulting in an $S / V$ ratio of $3.7 \mathrm{~m}^{-1}$. The details of the NIES smog chamber are described in the literature. ${ }^{20}$

The NIES smog chamber was filled with 760 Torr of dry 


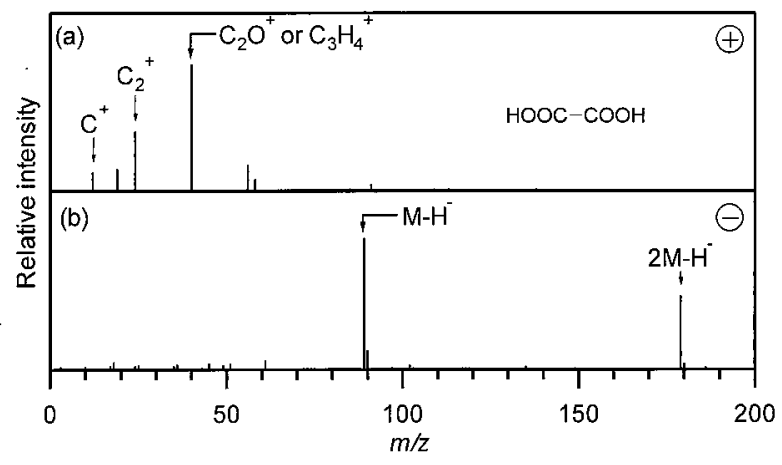

Fig. 2 Averaged (a) positive and (b) negative-ion mass spectra of oxalic acid $\left(M_{\mathrm{W}} 90\right)$ particles.

purified air prior to introducing the reactants. Ozone was introduced into the chamber from an ozone generator (Iwasaki, OP-20W). The reaction started by following the introduction of cyclohexene (99\% purity, Aldrich), which was used without further purification. The initial conditions for each run of the cyclohexene ozonolysis are given in Table 1. The reactant mixture was stirred well with a mixing fan for a few minutes after introducing cyclohexene into the chamber. Each run was performed in the dark under a dry condition (relative humidity < 1 ppmv) without any seed particles or hydroxyl radical scavengers, and was typically terminated within $\sim 60 \mathrm{~min}$. During each run, the SOA particles formed in the chamber were sampled through a $1 / 4$ inch diameter $\times \sim 3$ m length stainlesssteel tube, and were directly introduced to the LISPA-MS. By using a scanning mobility particle sizer instrument (SMPS; TSI, Model 3934), we confirmed that the SOA particles formed from the cyclohexene ozonolysis had a detectable size ( $~ 200 \mathrm{~nm}$ ) within a few minutes. The concentrations of the gaseous reactants were measured every $6 \mathrm{~min}$ by an FT-IR spectrometer (Nicolet, Nexus 670) equipped with a liquid $\mathrm{N}_{2}$-cooled MCT detector. The spectral resolution was $1.0 \mathrm{~cm}^{-1}$. The spectrometer was coupled to a white mirror system (base path $1700 \mathrm{~mm}$ ), which was operated at 130 traverses, giving a total absorption path length of $221.5 \mathrm{~m}$ including the transfer path. The details of SOA formation studies by using the NIES smog chamber are described in the literature..$^{17,21}$

\section{Generation of standard aerosol particles}

For the sake of analyzing the mass spectra of the SOA particles formed from the cyclohexene ozonolysis, standard particles generated from dicarboxylic acid solutions using an atomizer were measured by the LISPA-MS. Dicarboxylic acids are major products formed from cyclohexene ozonolysis. ${ }^{13,14}$ Dicarboxylic acids are also ubiquitous water-soluble organic compounds in atmospheric aerosol particles, and are produced from both primary sources ${ }^{22,23}$ and secondary atmospheric chemistry. ${ }^{24}$ Oxalic, malonic, maleic, and glutaric acids (>98\% purity, Wako Pure Chemical Industries) were used as standard dicarboxylic acids. Each dicarboxylic acid was dissolved in distilled water (about $1 \% \mathrm{w} / \mathrm{v})$. The solutions were atomized by using a compressed air nebulizer (about $3 \mathrm{~L} \mathrm{~min}^{-1}$ ) for generating standard aerosol particles. The generated aerosol particles passed through a home-built diffusion drier, which was filled with silica gel. The resultant dried aerosol particles were directly introduced to the LISPA-MS. The standard mass spectra of dicarboxylic acid particles described in this paper were obtained by averaging a minimum of 50 spectra, namely, 50 particles.

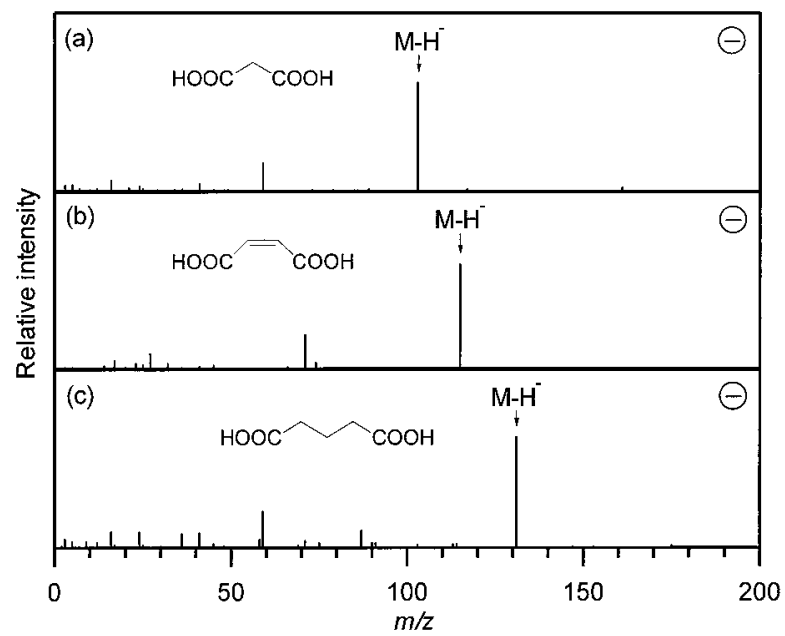

Fig. 3 Averaged negative-ion mass spectra of (a) malonic acid ( $M_{\mathrm{W}}$ $104)$, (b) maleic acid ( $\left.M_{\mathrm{W}} 116\right)$, and (c) glutaric acid $\left(M_{\mathrm{W}} 132\right)$ particles.

\section{Results and Discussion}

Mass spectra of dicarboxylic acid standard particles measured by the LISPA-MS

The averaged positive and negative-ion mass spectra of oxalic acid $\left(M_{\mathrm{W}} 90\right)$ standard particles are shown in Fig. 2. The negative-ion mass spectrum provides information about the molecular weight of oxalic acid, whereas the positive-ion mass spectrum contains almost no information about it. In the negative-ion spectrum, the most intense peak was observed at $\mathrm{m} / \mathrm{z}$ 89, as shown in Fig. 2b. This ion is a molecular-related negative ion $[\mathrm{M}-\mathrm{H}]^{-}$. Molecular-dimer-related ion $[2 \mathrm{M}-\mathrm{H}]^{-}$at $\mathrm{m} / \mathrm{z} 179$ also appeared with a definite signal intensity in the negative-ion spectrum. In the negative-ion spectrum, the signal intensities of fragment ions were weaker than that of $[\mathrm{M}-\mathrm{H}]^{-}$. In the positive-ion spectrum, the most intense peak was observed at $\mathrm{m} / \mathrm{z}$ 40, as shown in Fig. 2a. This ion can be attributed to $\mathrm{C}_{2} \mathrm{O}^{+}$or $\mathrm{C}_{3} \mathrm{H}_{4}^{+}$. The intense peaks observed at $\mathrm{m} / \mathrm{z}$ 12 and 24 in the positive-ion spectrum are attributable to carbon cluster ions $\left(\mathrm{C}_{\mathrm{n}}^{+}\right)$.

Figure 3 shows the averaged negative-ion mass spectra of malonic acid $\left(M_{\mathrm{W}} 104\right)$, maleic acid $\left(M_{\mathrm{W}} 116\right)$, and glutaric acid $\left(M_{\mathrm{W}}\right.$ 132) standard particles. In the negative-ion spectra, molecular-related ions $[\mathrm{M}-\mathrm{H}]^{-}($at $\mathrm{m} / \mathrm{z} \quad 103,115$, and 131 in Figs. 3a, 3b, and 3c, respectively) were obviously observed with remarkable intensities, although a few fragment ions were observed. The dominant molecular-related ions $[\mathrm{M}-\mathrm{H}]^{-}$in the negative-ion mass spectra for strait-chain dicarboxylic acid particles were found for the first time. These results indicate that organic compounds containing carboxyl group in aerosol particles provide intense molecular-related ions $[\mathrm{M}-\mathrm{H}]^{-}$and a few weak fragment ions in the negative-ion mass spectra under our experimental conditions, so that their molecular weights, namely, parent molecules can be inferred through observations of molecular-related ions in the negative-ion spectra. The positive-ion mass spectra of those compound particles were similar to that of oxalic acid.

\section{Mass spectra of SOA particles measured by the LISPA-MS}

Figure 4 shows temporal profile of cyclohexene and ozone concentrations in the cyclohexene ozonolysis. The reaction well proceeded within $60 \mathrm{~min}$. The representative positive and negative-ion mass spectra of single SOA particles are shown in 


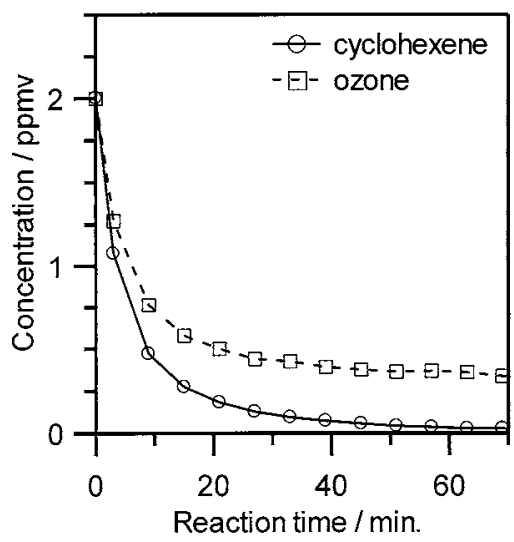

Fig. 4 Temporal profile of the concentrations of cyclohexene $(O)$ and ozone ( $\square$ ) in cyclohexene ozonolysis (run No. 1) conducted in the NIES smog chamber.

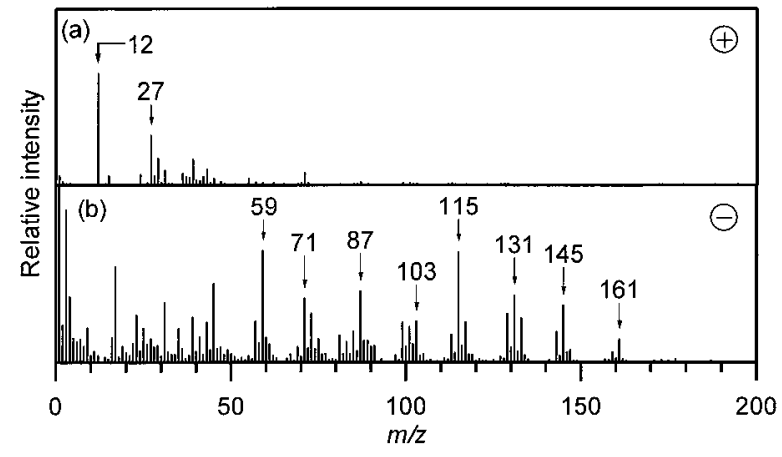

Fig. 5 Representative mass spectra obtained from each single SOA particle formed from cyclohexene ozonolysis. (a) Positive ion (run No. 1, $5.3 \mathrm{~min}$ ) and (b) negative ion (run No. 1, 4.0 min).

Fig. 5. The $m / z$ values, observed as intense ions in the positiveion spectra, were fragment ions, as discussed above for the dicarboxylic acid standard particles. The ions at odd $\mathrm{m} / \mathrm{z}$ were more intense than those at even $\mathrm{m} / \mathrm{z}$ in the negative-ion spectra, suggesting that the ions are formed by the elimination of a proton $\left(\mathrm{H}^{+}\right)$, because hydrocarbons and oxygenated hydrocarbons have even molecular weights.

SOA formation from cyclohexene ozonolysis has been studied extensively. ${ }^{13-18}$ Because cyclohexene has a double bond in the six-membered ring, $\mathrm{O}_{3}$ can attack the double bond, leading to an energy-rich Criegee intermediate. ${ }^{25}$ The following reactions of the intermediates form organic compounds with two functional groups (aldehyde and/or carboxyl groups) as the major products. Table 2 lists the $\mathrm{m} / \mathrm{z}$, values observed as intense ions in the negative-ion spectra, and their possibly corresponding mass $\left(M_{\mathrm{W}} \geq 50\right)$. The compounds, which have the corresponding mass and are reported as major particulate products formed from cyclohexene ozonolysis, ${ }^{14,16,18}$ are also listed in Table 2 along with those structures. In the negative-ion mass spectra, the ions formed by proton elimination of the major particulate products formed from the cyclohexene ozonolysis were observed as intense mass peaks. For example, adipic, glutaric, and 5-oxo-pentanoic acids ( $M_{\mathrm{W}} 146,132$ and 116, respectively) are major particulate products, ${ }^{13,14,16}$ and their molecular-related ions $[\mathrm{M}-\mathrm{H}]^{-}(\mathrm{m} / \mathrm{z}, 145,131$, and 115) were obviously observed as intense mass peaks in the negative-ion spectra, as shown in
Table 2 Intense mass peaks $(\mathrm{m} / \mathrm{z})$ in negative-ion mass spectra of the SOA particles and possibly corresponding mass $\left(M_{\mathrm{W}} \geq 50\right)$

\begin{tabular}{|c|c|c|c|}
\hline$m / z$ & Mass & Compound $^{a}$ & Structure $^{a}$ \\
\hline 57 & 58 & $-^{\mathrm{b}}$ & \\
\hline 59 & 60 & $-^{\mathrm{b}}$ & \\
\hline 71 & 72 & Butanal & \\
\hline 73 & 74 & Propanoic acid & $\mathrm{COOH}$ \\
\hline 81 & 82 & $-^{\mathrm{b}}$ & \\
\hline 85 & 86 & 1,4-Butanedial & $\mathrm{CHO}$ \\
\hline 87 & 88 & Butanoic acid & $\mathrm{COOH}$ \\
\hline 89 & 90 & Oxalic acid & $\mathrm{HOOC}-\mathrm{COOH}$ \\
\hline 99 & 100 & 1,5-Pentanedial & $\mathrm{CHO}$ \\
\hline 101 & 102 & 4-Oxo-butanoic acid & $\mathrm{COOH}_{\mathrm{COH}}$ \\
\hline 103 & 104 & Malonic acid & $\mathrm{COOH}$ \\
\hline 113 & 114 & 1,6-Hexanedial & $\smile_{\mathrm{CHO}}$ \\
\hline 115 & 116 & 5-Oxo-pentanoic acid & $\mathrm{COOH}$ \\
\hline 117 & 118 & Succinic acid & $\mathrm{COOH}$ \\
\hline 129 & 130 & 6-Oxo-hexanoic acid & $\mathrm{OHC}$ \\
\hline 131 & 132 & Glutaric acid & ноОс \\
\hline 133 & 134 & Hydroxy succinic acid & $\mathrm{OH}$ \\
\hline 143 & 144 & Dioxo-hexanoic acid & \\
\hline 145 & 146 & Adipic acid & ноос \\
\hline 147 & 148 & Hydroxy glutaric acid & $\mathrm{HOOC}^{-}$ \\
\hline 159 & 160 & Oxo-adipic acid & \\
\hline 161 & 162 & Hydroxy adipic acid & \\
\hline
\end{tabular}

a. Compounds and structures of the corresponding mass are reported as major particulate products formed from cyclohexene ozonolysis. ${ }^{13,14,18}$

b. No assigned to the reported products formed from cyclohexene ozonolysis.

Fig. 5b. Most of the intense mass peaks in the negative-ion spectra can be assigned to the compounds reported as particulate products from cyclohexene ozonolysis, ${ }^{14,16,18}$ whereas the mass peaks at $m / z, 57,59$, and 81 may not be assigned to the known products. It is likely that most of the ions appearing in the negative-ion spectra of the SOA particles consist of molecular-related ions $[\mathrm{M}-\mathrm{H}]^{-}$formed by proton elimination from the reaction products and fragment ions, as discussed above for the dicarboxylic acid standard particles. Therefore, the negative-ion mass spectra provide important information to investigate the SOA formation processes.

The $\mathrm{C}_{2}-\mathrm{C}_{6}$ dicarboxylic acids are formed by the following reaction of the Criegee intermediate formed from cyclohexene ozonolysis, as shown in Fig. $6 .^{13-15}$ The relationships between the signal intensities of the ions derived from $\mathrm{C}_{4}-\mathrm{C}_{6}$ dicarboxylic acids are shown in Fig. 7. The signal intensities of the ions in Fig. 7 are normalized from $\mathrm{m} / \mathrm{z}, 51$ to 200. The ions at $m / z, 145$ (adipic acid: $\mathrm{C}_{6}, \mathrm{~A}$ in Fig. 6) were correlated with those at $m / z 131$ (glutaric acid: $\mathrm{C}_{5}$, B in Fig. 6) $\left(r^{2}=0.79\right)$, as shown in Fig. 7a, while the ions at $\mathrm{m} / \mathrm{z} 131$ were not well correlated with those at $\mathrm{m} / \mathrm{z} 117$ (succinic acid: $\mathrm{C}_{4}, \mathrm{C}$ in Fig. 6) $\left(r^{2}=0.47\right)$, as shown in Fig. 7b. The good correlation between $\mathrm{m} / \mathrm{z} 145$ and 131 indicates that the ratios of adipic and glutaric acids in the individual SOA particles are almost the same 


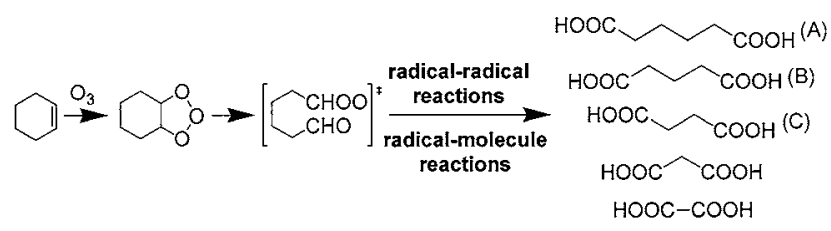

Fig. 6 Formation of $\mathrm{C}_{2}-\mathrm{C}_{6}$ dicarboxylic acids in cyclohexene ozonolysis. The double dagger $\neq$ denotes an energy-rich Criegee intermediate.

throughout the reaction. The result between adipic and glutaric acids in our present study is consistent with that reported by Hatakeyama et al. ${ }^{13}$ They observed that the ratio of the total $\mathrm{C}_{5}$ compounds to the total $\mathrm{C}_{6}$ compounds in particulate products in cyclohexene ozonolysis is constant and independent of the reaction time. ${ }^{13}$ The formation pathways of adipic and glutaric acids are probably analogous throughout the reaction. ${ }^{13,15}$ The poor correlation between $\mathrm{m} / \mathrm{z}, 131$ and 117 indicates that the ratios of glutaric and succinic acids in the individual SOA particles are variable while the reaction proceeds. The result between glutaric and succinic acids might suggest that the formation pathways of the $\mathrm{C}_{5}$ and $\mathrm{C}_{6}$ dicarboxylic acids and $\mathrm{C}_{2}-$ $\mathrm{C}_{4}$ dicarboxylic acids are different.

The ions at $m / z 161$ and 147, which are derived from hydroxyadipic acid $\left(M_{\mathrm{W}} 162\right)$ and hydroxy-glutaric acid $\left(M_{\mathrm{W}} 148\right)$, respectively, were observed in the negative-ion mass spectra, as shown in Fig. 5b. Hydroxy-dicarboxylic acids are major particulate products formed from cyclohexene ozonolysis; ${ }^{14,16,18}$ however, the formation mechanisms of hydroxy-dicarboxylic acids are not well understood. Aschmann et al. ${ }^{26}$ reported that hydroxy-1,6-hexanedial ( $\left.M_{\mathrm{W}} 130\right)$, which can be the precursor of hydroxy-adipic acid, is a gaseous product formed from cyclohexene ozonolysis. However, hydroxy-1,5-pentanedial $\left(M_{\mathrm{W}} 116\right)$, which can be the precursor of hydroxy-glutaric acid, is not detected in the gaseous products in their study. ${ }^{26}$ In our present study, the ions at $\mathrm{m} / \mathrm{z} 161$ (hydroxy-adipic acid) were not well correlated with those at $\mathrm{m} / \mathrm{z} 147$ (hydroxy-glutaric acid) $\left(r^{2}=0.49\right)$. The results reported by Aschmann et al. ${ }^{26}$ and our result suggest that the formation mechanisms of hydroxy-adipic and hydroxy-glutaric acids are different, whereas the formation mechanisms of adipic and glutaric acids are analogous, as described in the previous section.

Distributions of the ion signal intensities in the negative-ion mass spectra changed as a function of the reaction time. Figure 8 shows the averaged negative-ion spectra of twenty SOA particles (a) at the beginning of the reaction $(\sim 3 \mathrm{~min}$ from the start of the reaction) and (b) after the reaction had well proceeded ( $\sim 63 \mathrm{~min}$ from the start of the reaction). The signal intensity ratios at $\mathrm{m} / \mathrm{z}, 145$ (adipic acid) to 129 (6-oxo-hexaonic acid) and at $\mathrm{m} / \mathrm{z} 131$ (glutaric acid) to 115 (5-oxo-pentanoic acid) are different between the two spectra, as shown in Fig. 8. The ratios of $\mathrm{m} / \mathrm{z} 145$ to 129 are $1.4 \pm 0.6$ for Fig. 8 a ( $\sim 3 \mathrm{~min})$ and $1.9 \pm 0.6$ for Fig. $8 \mathrm{~b}(\sim 63 \mathrm{~min})$. The ratios of $\mathrm{m} / \mathrm{z} 131$ to 115 are $0.6 \pm 0.4$ for Fig. 8 a $(\sim 3 \mathrm{~min})$ and $1.8 \pm 0.9$ for Fig. $8 b$ ( $\sim 63 \mathrm{~min})$. The increase of those ratios support that dicarboxylic acids are formed by the oxidation of oxo-carboxylic acids as a function of the reaction time; namely, the oxidation of the SOA particles proceeds with the reaction time. ${ }^{13}$

\section{Conclusions}

In this paper, we have presented the application of the LISPA-
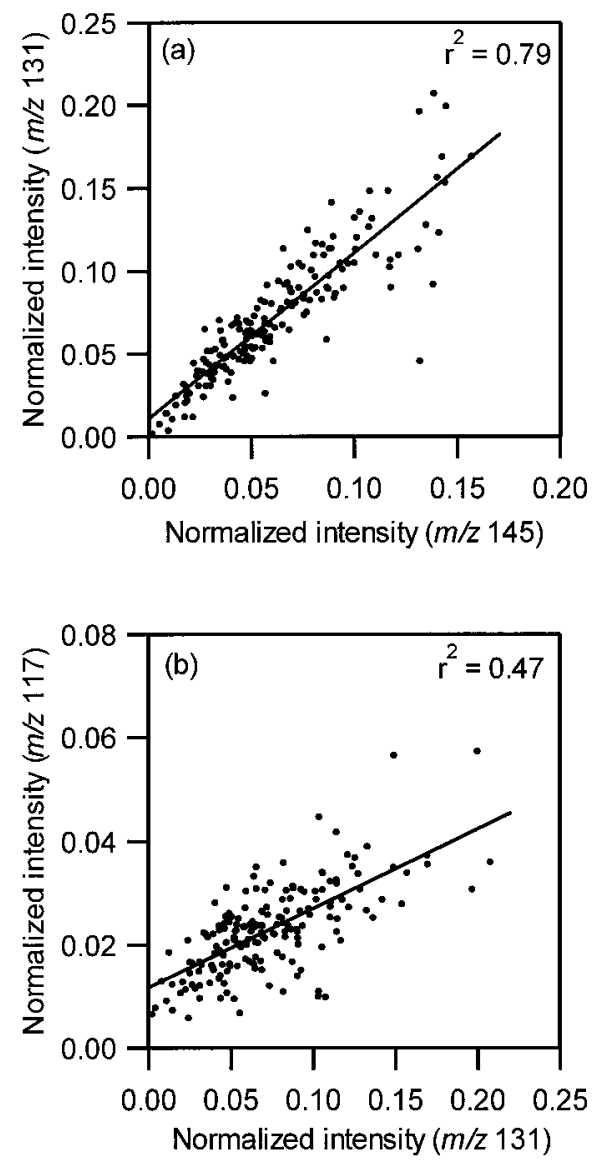

Fig. 7 Relationships between the ions (a) at $\mathrm{m} / \mathrm{z}, 145$ (adipic acid; A in Fig. 6) and 131 (glutaric acid; B in Fig. 6), and (b) at $m / z, 131$ and 117 (succinic acid; $C$ in Fig. 6) in negative-ion mass spectra of the SOA particles. The signal intensities of the ions are normalized from $\mathrm{m} / \mathrm{z}, 51$ to 200. Data obtained from all experiments (run No. $1-4$ ) were put together.

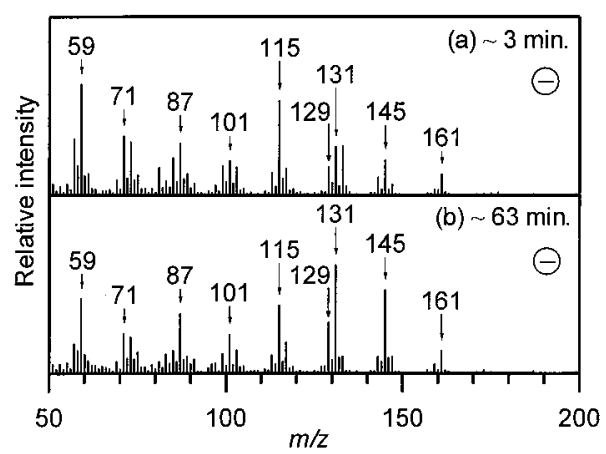

Fig. 8 Negative-ion mass spectra of the SOA particles (a) at the beginning of the reaction (average of twenty spectra obtained at $\sim 3$ min) and (b) after the reaction had well proceeded (average of twenty spectra obtained at $\sim 63 \mathrm{~min})$. Data obtained from all experiments (run No. 1 - 4) were put together and averaged.

MS technique to study of SOA particles formed from cyclohexene ozonolysis. For the sake of analyzing the spectra of the SOA particles, the standard particles generated from solutions of dicarboxylic acids, which are major particulate products from cyclohexene ozonolysis, were also analyzed by the LISPA-MS. We showed that the negative-ion mass spectra 
of the dicarboxylic acid standard particles were characterized by intense molecular-related ions $[\mathrm{M}-\mathrm{H}]^{-}$, while the positive-ion mass spectra of those were by fragment ions. The mass spectral analysis of the SOA particles indicated that most of the intense mass peaks in the negative-ion spectra also consisted of molecular-related ions $[\mathrm{M}-\mathrm{H}]^{-}$of the reaction products. The correlation between the ion signal intensities in the negative-ion spectra of the SOA particles provide information about the formation reaction pathway of dicarboxylic and hydroxydicarboxylic acids in the cyclohexene ozonolysis. The distributions of intense ions in the negative-ion spectra varied as a function of the reaction time, suggesting that the SOA particles are oxidized as a reaction of time. We demonstrated that the real-time single-particle analysis of the individual SOA particles with high time-resolution by the LISPA-MS technique can be used to investigate the formation and transformation processes of SOA particles in smog chambers.

\section{Acknowledgements}

This work was supported by SENTAN, Japan Science and Technology Agency (JST).

\section{References}

1. P. Saxena and L. M. Hildemann, J. Atmos. Chem., 1996, 24, 57.

2. M. Kanakidou, J. H. Seinfeld, S. N. Pandis, I. Barnes, F. J. Dentener, M. C. Facchini, R. Van Dingenen, B. Ervens, A. Nenes, C. J. Nielsen, E. Swietlicki, J. P. Putaud, Y. Balkanski, S. Fuzzi, J. Horth, G. K. Moortgat, R. Winterhalter, C. E. L. Myhre, K. Tsigaridis, E. Vignati, E. G. Stephanou, and J. Wilson, Atmos. Chem. Phys., 2005, 5, 1053.

3. J. H. Seinfeld and J. F. Pankow, Annu. Rev. Phys. Chem., 2003, 54, 121.

4. B. J. Turpin, P. Saxena, and E. Andrews, Atmos. Environ., 2000, 34, 2983.

5. D. S. Thomson, M. E. Schein, and D. M. Murphy, Aerosol Sci. Technol., 2000, 33, 153.

6. E. Gard, J. E. Mayer, B. D. Morrical, T. Dienes, D. P. Fergenson, and K. A. Prather, Anal. Chem., 1997, 69, 4083.

7. R. V. Mallina, A. S. Wexler, K. P. Rhoads, and M. V. Johnston, Aerosol Sci. Technol., 2000, 33, 87.

8. J. T. Jayne, D. C. Leard, X. Zhang, P. Davidovits, K. A. Smith, C. E. Kolb, and D. R. Worsnop, Aerosol Sci.
Technol., 2000, 33, 49.

9. A. M. Middlebrook, D. M. Murphy, S.-H. Lee, D. S. Thomson, K. A. Prather, R. J. Wenzel, D.-Y. Liu, D. J. Phares, K. P. Rhoads, A. S. Wexler, M. V. Johnston, J. L. Jimenez, J. T. Jayne, D. R. Worsnop, I. Yourshaw, J. H. Seinfeld, and R. C. Flagan, J. Geophys. Res., 2003, 108, 8424.

10. D. G. Nash, T. Baer, and M. V. Johnston, Int. J. Mass. Spectrom., 2006, 258, 2.

11. D. M. Murphy, Mass Spectrom. Rev., 2007, 26, 150.

12. J. Matsumoto, K. Takahashi, Y. Matsumi, A. Yabushita, A. Shimizu, I. Matsui, and N. Sugimoto, Geophys. Res. Lett., 2006, 33, L07816.

13. S. Hatakeyama, T. Tanonaka, J.-H. Weng, H. Bandow, H. Takagi, and H. Akimoto, Environ. Sci. Technol., 1985, 19, 935.

14. M. Kalberer, J. Yu, D. R. Cocker, R. C. Flagan, and J. H. Seinfeld, Environ. Sci. Technol., 2000, 34, 4894.

15. P. J. Ziemann, J. Phys. Chem. A, 2002, 106, 4390.

16. S. Gao, M. Keywood, N. L. Ng, J. Surratt, V. Varutbangkul, R. Bahreini, R. C. Flagan, and J. H. Seinfeld, J. Phys. Chem. A, 2004, 108, 10147.

17. K. Sato, Chem. Lett., 2005, 34, 1584.

18. J. F. Hamilton, A. C. Lewis, J. C. Reynolds, L. J. Carpenter, and A. Lubben, Atmos. Chem. Phys., 2006, 6, 4973.

19. X. Zhang, K. A. Smith, D. R. Worsnop, J. Jimenez, J. T. Jayne, and C. E. Kolb, Aerosol Sci. Technol., 2002, 36, 617.

20. H. Akimoto, M. Hoshino, G. Inoue, F. Sakamaki, N. Washida, and M. Okuda, Environ. Sci. Technol., 1979, 13, 471.

21. K. Sato, B. Klotz, S. Hatakeyama, T. Imamura, Y. Washizu, Y. Matsumi, and N. Washida, Bull. Chem. Soc. Jpn., 2004, 77, 667.

22. K. Kawamura and I. R. Kaplan, Environ. Sci. Technol., 1987, 21, 105.

23. M. Narukawa, K. Kawamura, N. Takeuchi, and T. Nakajima, Geophys. Res. Lett., 1999, 26, 3101.

24. D. Grosjean and S. K. Friedlander, Adv. Environ. Sci. Technol., 1980, 9, 435.

25. J. G. Calvert, R. Atkinson, J. A. Kerr, S. Madronich, G. K. Moortgat, T. J. Wallington, and G. Yarwood, "The Mechanisms of Atmospheric Oxidation of the Alkenes", 2000, Oxford University Press, New York.

26. S. M. Aschmann, E. C. Tuazon, J. Arey, and R. Atkinson, J. Phys. Chem. A, 2003, 107, 2247. 